\title{
Analysis of the impact of tension on automobile synchronous belt transverse natural frequency
}

\author{
Cai Yunguang ${ }^{1, a}$, Chen Sisi ${ }^{2, b}$, Li Zhanguo ${ }^{2, c}$ and Shi Yaochen ${ }^{1, d}$ \\ ${ }^{1}$ Changchun University, Changchun ,China, 130022. \\ ${ }^{2}$ Changchun University of Technology,Changchun, China ,130012 \\ a279309014@qq.com, b250793721@qq.com, 555917237@qq.com, 'shiyaochen126@126.com
}

\begin{abstract}
Keywords: Automobile synchronous belt; Transverse vibration; Natural frequency
Abstract. The vibration of belt in the process of automobile synchronous belt transmission directly influence transmission smoothness, and produce noise and affect the service life of the belt. In this paper, through the establishment of mathematical model of belt transverse vibration in the process of synchronous belt transmission, solving impact of tension on transverse vibration natural frequency; As the same time, designing a synchronous belt transverse vibration natural frequency measuring device in order to measure the transverse vibration natural frequency when the tension is from $300 \mathrm{~N}$ to $1000 \mathrm{~N}$, so as to verify the mathematical model about impact of tension on transverse vibration natural frequency, provide the foundation for choice of tension in the process of automotive multi-pulley synchronous belt design, and have a certain significance on reducing the noise in the transmission process and prolonging the service life of belt .
\end{abstract}

\section{Introduction}

By reason of the advantages of simple structure 、 low price 、 easy installation 、 without lubrication 、 noise reduction and vibration absorption, the synchronous belt is widely used in automobile engine timing driving system; Currently, trapezoidal tooth synchronous belt is commonly used in automobile engine, and which can be divided into types of ZA and ZB according to the size of the load; the ZA type automobile synchronous belt pitch is $9.525 \mathrm{~mm}$, and it is mainly used in gasoline engine. Belt teeth mesh with belt pulley in the process of synchronous belt transmission, which generates impact and vibration,thus effect stability and service life of the belt drive. In order to further reduce vibration and noise in the transmission process, While designing synchronous belt transmission system, we should choose the appropriate parameters such as material quality, rotational speed and tension, so as to avoid to produce resonance in the process of transmission by avoiding the natural frequency of the belt drive system. With the purpose of avoiding to produce resonance and improving stability and service life of automobile synchronous belt transmission, scholars at home and abroad study and experimental analysis vibration in the process of synchronous belt transmission. In 2003, Yang Yuping establish a synchronous belt transverse vibration motion equation, solve the natural frequency of transverse vibration, and make the calculation results corrected ${ }^{[1]}$. In 2007 , In view of 469Q engine timing driving system, Wang Yanhua simplify multi-pulley synchronous belt drive system to the beam model, calculate the natural frequency of the belt, and measure the resonance phenomenon with the driving wheel rotational speed at 3500rpm 4200rpm by the strain type contact displacement sensor ${ }^{[2]}$. In 2009, Gregor Cepon simplify belt drive to plane beam element, use ANCF algorith to solve the parameters of the ribbed belt drive system such as stiffness coefficient and damping coefficient, and measure the stiffness coefficient and damping coefficient coincided well with calculation results by laser displacement sensor ${ }^{[3]-[6]}$.

\section{The establishment of synchronous belt transverse vibration model}

Synchronous belt is an elastomer transmission part,in the process of transmission, producing transverse and longitudinal vibration. As shown in figure 1, taking the pitch line of belt and tangent point of pitch circle on driving pulley as the origin of coordinate $\mathrm{O}$, along the movement direction of 
the synchronous belt as $\mathrm{X}$ axis that is the direction of longitudinal vibration, perpendicular to the direction on the surface of the belt as the $\mathrm{Y}$ axis that is the direction of transverse vibration, along the direction of the axis of the pulley for $\mathrm{Z}$ axis, and then building a coordinate systeme.
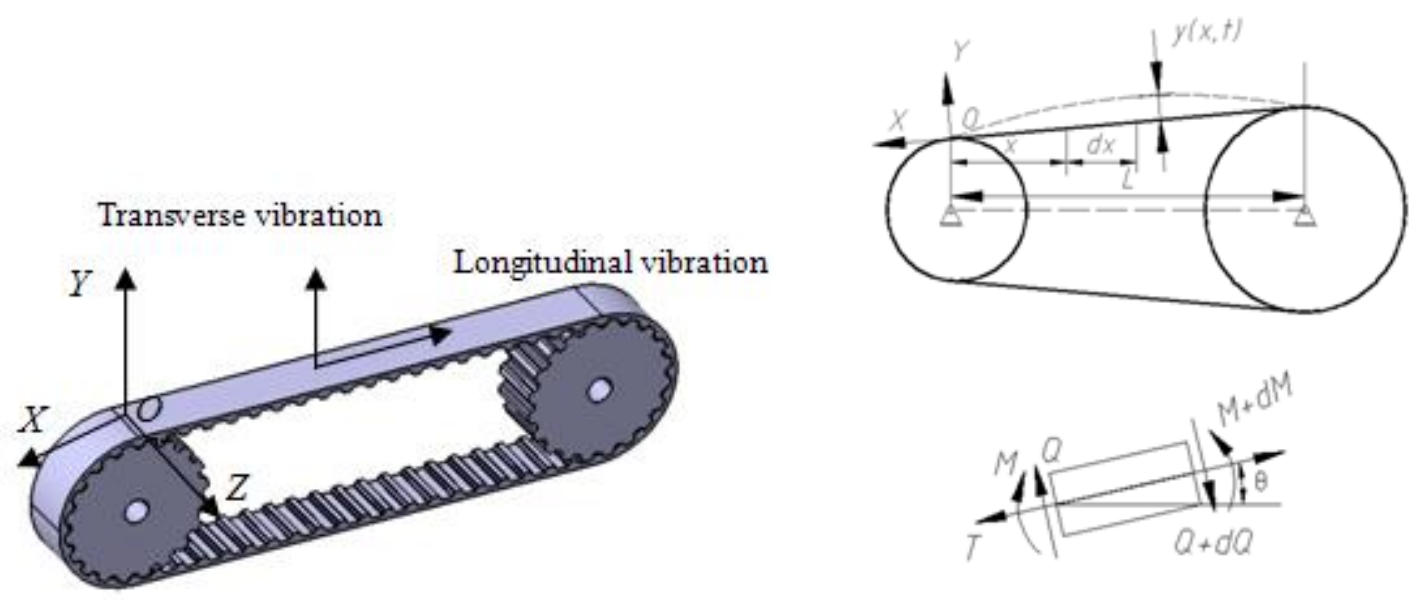

Fig.1 the sketch of synchronous belt vibration

Fig. 2 Model of synchronous belt vibration

The amplitude of transverse vibration is the largest in the process of synchronous belt transmission. So the transverse vibtation is the main factor about influencing the stability of transmission and the service life, and making noise. According to the above, this paper mainly studies synchronous belt transverse vibration. As shown in figure 2, seting the equilibrium position of synchronous belt transverse vibration to the $\mathrm{X}$ axis, and the tangent point of pitch circle on pully to the origin of coordinate $\mathrm{O}$.

To set tension on every belt as $\mathrm{T}$, the mass of unit length belt as $\rho$, the flexural rigidity of section area as EI. Analyzing synchronous belt infinitesimal that is a length of dx away from the origin $\mathrm{x}$, there are shear $\mathrm{Q}$ and $\mathrm{Q}+\mathrm{dQ}$, bending moment $\mathrm{M}$ and $\mathrm{M}+\mathrm{dM}$, tension $\mathrm{T}$ on both sides of the infinitesimal. At time $\mathrm{t}$, the force balance equation on $\mathrm{Y}$ direction and the torque balance equation on left section of infinitesimal,as equation(1) and (2) shown below:

$$
\begin{aligned}
& Q \cos \theta(x, t)-\left(Q+\frac{\partial Q}{\partial x} d x\right) \cos \theta(x+d x, t)+T \sin \theta(x+d x, t)-T \sin \theta(x, t)=\rho d x \frac{\partial^{2} y}{\partial t^{2}} \\
& \left(M+\frac{\partial M}{\partial x} d x\right)-M-\left(Q+\frac{\partial Q}{\partial x} d x\right) d x=0
\end{aligned}
$$

Set equation $y(x, t)$ as $y(x, t)=A \sin (n \pi x / L) e^{(i \omega t)}$, and the following simplified:

$$
\begin{aligned}
& \sin \theta(x, t) \approx \frac{\partial y(x, t)}{\partial x} \\
& \sin \theta(x+d x, t) \approx \frac{\partial y(x, t)}{\partial x}+\frac{\partial^{2} y(x, t)}{\partial x^{2}} d x \\
& \cos \theta(x, t) \approx \cos \theta(x+d x, t) \approx 1 \\
& E I \frac{\partial^{2} y(x, t)}{\partial x^{2}}=M(x, t)
\end{aligned}
$$

The synchronous belt natural frequency under tension can be written as:

$$
\omega_{s n}{ }^{2}=(n \pi / L)^{2}(T / \rho)+(n \pi / L)^{4}(E I / \rho)
$$

Through equation (7), we could find that in the case of other parameters remain the same, natural frequency of the synchronous belt increase with tension, but excessive tension may also affect the service life of the synchronous belt.

\section{Test method for synchronous belt transverse vibration}


In order to verify the impact of tension on natural frequency, in this paper, in view of ZA type automobile synchronous belt, we use the heavy hammer excitation method for transverse natural frequency measurement test on the tensile testing machine. As shown in figure 3, through the two pulley, teeth of 22, center distance $323.85 \mathrm{~mm}$, ZA type automobile synchronous belt, the bandwidth of $19.1 \mathrm{~mm}$, teeth of 90 , installed in the tensile test machine; through the tensile testing machine, the beam exert tension on synchronous belt. In addition, acceleration signal acquisition device adopts Kisler company 8690C50 type three-way acceleration sensor, acceleration range form $-50 \mathrm{~g}$ to $+50 \mathrm{~g}$, sensitivity of $100 \mathrm{mv} / \mathrm{g}$, frequency response from 1 to $6000 \mathrm{~Hz}$. Digital signal processing instrument adopts INV306U type signal analyzer from Beijing Oriental institute of vibration and noise technology.

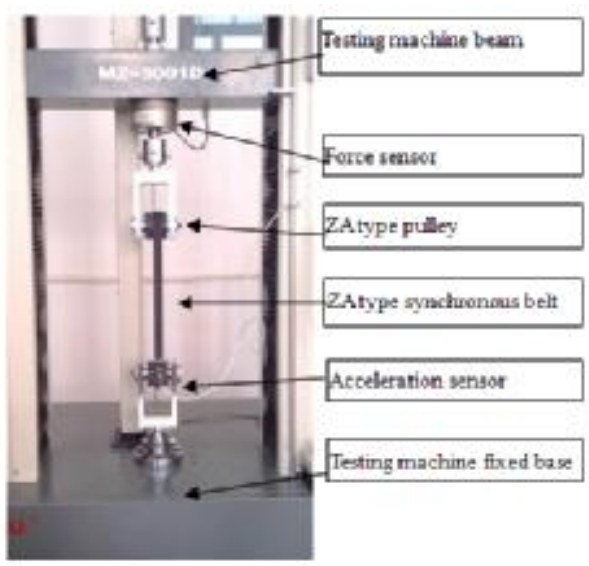

Fig.3 Belt natural frequency measurement

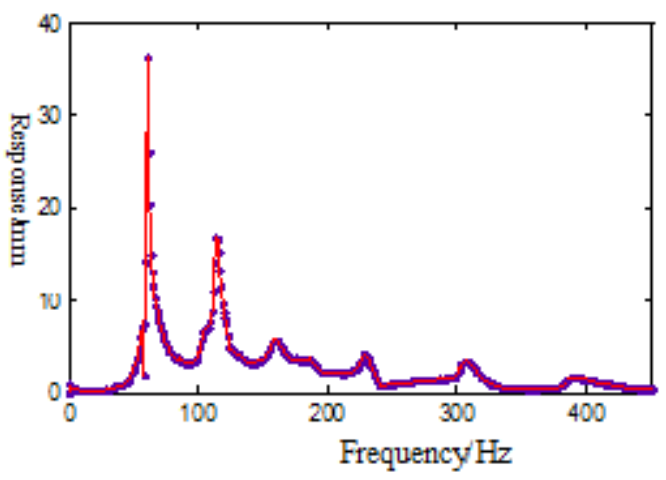

Fig.4 Frequency response curve of $300 \mathrm{~N}$

Firstly, we exert tension of $300 \mathrm{~N}$ on synchronous belt by tensile test machine; secondly, Using heavy hammer to apply excitation to the belt; lastly, by acceleration sensor, we obtain the time-domain signal of belt vibration which is converted to frequency response curve by FFT processing. As shown in figure 4, it can be seen that the first-order vibration frequency is about $62 \mathrm{~Hz}$, and the second-order frequency is about $120 \mathrm{~Hz}$.

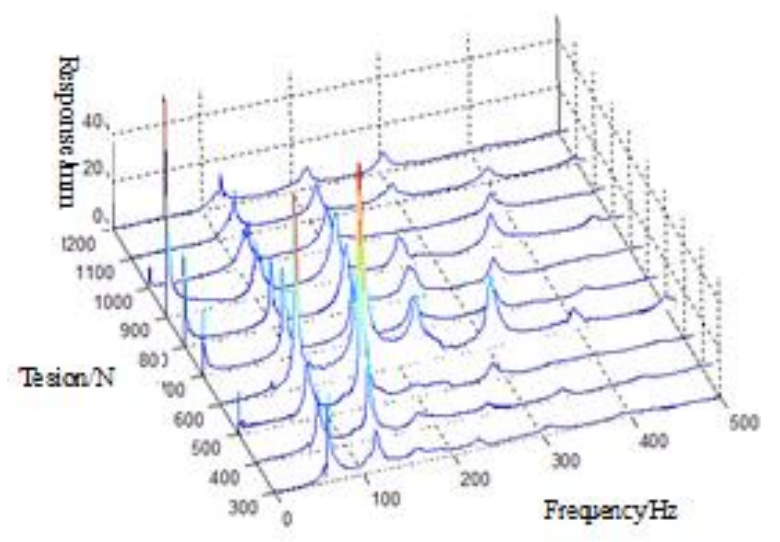

Fig5. The impact of tension on frequency response curve
Table 1. Test and calculation results of natural frequency under different tension

\begin{tabular}{ccccc}
\hline \multirow{2}{*}{ Tension } & \multicolumn{2}{c}{$\begin{array}{c}\text { Calculation results of } \\
\text { natural frequency }(\mathrm{Hz})\end{array}$} & \multicolumn{2}{c}{ Test results of } \\
& $1^{\text {st }}$ order & $2^{\text {nd }}$ order & $1^{\text {st }}$ order & $2^{\text {nd }}$ order \\
\hline $300 \mathrm{~N}$ & 60 & 120 & 61.992 & 118.985 \\
$600 \mathrm{~N}$ & 85.1 & 170.2 & 84.983 & 168.98 \\
& & & & \\
$900 \mathrm{~N}$ & 104 & 208 & 100.987 & 208.976 \\
& & & & \\
$1200 \mathrm{~N}$ & 120 & 240 & 121.984 & 236.972
\end{tabular}

Since pulley center distance has been fixed according to the arrangement of pulleys in the process of multi-pulley synchronous belt design and most of the synchronous belt materials are polyester rubber or glass fiber cord, elastic modulus and density is also fixed according to the choice of 
materials. Adjusting the tension can change natural frequency of synchronous belt drive system and avoid rotational speed of the belt so as to avoid to produce vibration. In order to analyze impact of tension on natural frequency of drive system, we use the same test method in tensile testing machine that respectively exerting tension of $300 \mathrm{~N}, 600 \mathrm{~N}, 900 \mathrm{~N}$ and $1200 \mathrm{~N}$ to measure the natural frequency. The frequency response curve obtained by measure is shown in figure 5 .

To verify the theoretical analysis about the impact of tension on automobile synchronous belt transverse natural frequency,comparing the test results with calculation results, as shown in table 1, we can find that natural frequency increases with tension, and the calculation results gained by equation 7 are consistent with the test results.

\section{Conclusions}

In this paper,in view of the type ZA automotive synchronous belt, through the establishment of equation about transverse vibration in the process of synchronous belt transmission, we solve synchronous belt transverse vibration natural frequency, and analyze the impact of tension on it.Bisides, adopting the heavy hammer excitation method to measure the transverse vibration natural frequency under different tension value, and verifying the impact of tension on it, which have a certain significance on choice of tension in the process of automotive multi-pulley synchronous belt design

\section{References}

[1] Yang Yuping,Zhang Xiaomei,Shen Shide, Transverse vibration analysis of synchronous belt drive system [J], Mechanical design, (2003)01:27-30.

[2] Wang Yanhua, Qiao Anping, Synchronous belt transverse vibration research of 469Q automobile gasoline engine [J]. Journal of internal combustion engine. 2007.25(2):186-190.

[3] Gregor Cepona, LionelManinb, MihaBoltezar. Introduction of damping into the flexible multibody belt-drive model: A numerical and experimental investigation[J], Journal of Sound and Vibration 324 (2009) 283 - 296.

[4] Wen-Bin Shangguan Modeling and Validation of Rotational Vibration Responses for Accessory Drive Systems - Part I: Experiments and Belt Modeling, Transactions of the ASME, 2013.7vol135: :01002-113.

[5] M. CALlEGARI, F. CANNELLA, Lumpered Parameter Model of Timing Belt Tranmasion [J],Mechanism and Machine Theory 44 (2009) 813 - 821.

[6] J MOON AND J A WICKERT, NON-LINEAR VIBRATION OF POWER TRANSMISSION BELTS[J], Journal of Sound and Vibration 1993.8: 308-320. 